\title{
Investigation on Inorganic Pollution Level in Surface Se- diments of Naples and Salerno Bay
}

\author{
Menghan Wang ${ }^{1}$, Benedetto De Vivo ${ }^{1}$, Stefano Albanese ${ }^{1}$, Annamaria Lima ${ }^{1}$, \\ Wanjun Lu' ${ }^{2}$, Flavia Molisso ${ }^{3}$, Marco Sacchi ${ }^{3}$ \\ 1Dipartimento di Scienze della Terra Università di Napoli Federico II, Napoli, Italy \\ ${ }^{2}$ Department of Marine Science, Faculty of Earth Resource, China University of Geosciences, Wuhan, China \\ ${ }^{3}$ C.N.R. Istituto Geomare Sud, Napoli, Italy \\ Email: menghan.wang@unina.it
}

Received 2013

\begin{abstract}
In this study, superficial marine sediments collected from 96 sampling sites were analyzed for 53 inorganic elements. Each sample was digested in aqua regia and analyzed by ICP-MS. A developed multifractal inverse distance weighted (IDW) interpolation method was applied for the compilation of interpolated maps for both single element and factor scores distributions. R-mode factor analysis has been performed on 23 of 53 analyzed elements. The 3 factor model, accounting $84.9 \%$ of data variability, were chosen. The three elemental associations obtained have been very helpful to distinguish anthropogenic from geogenic contribution. The aim of this study is to distinguish distribution patterns of pollutants on the sea floor of Naples and Salerno bays. In general, local lithologies, water dynamic and anthropogenic activities determine the distribution of the analyzed elements. To estimate pollution level in the area, Italian guidance, Canadian sediment quality guidance and Long's criteria are chosen to set the comparability. As the result shows, arsenic and lead may present highly adverse effect to living creatures.
\end{abstract}

Keywords: Pollution Level; Compositional Data Analysis; Factor Analysis; Napoli and Salerno Gulf

\section{Introduction}

Naples bay is a 10-mile wide gulf located in the south western coast of Italy, while Salerno bay is a gulf of Tyrrhenian Sea and separated from Naples bay by Sorrento Peninsula. Industrial complexes, intense commercial and transport activities insist on this area, which makes it potentially a heavily polluted coastal district and in need of remediation activities. Sediments are considered as a suitable medium to distinguish contamination and geochemical background of marine environment, since they are the pool of different deposition source and are a more stable medium than sea water. Moreover, toxic contaminants prefer to adsorb on sediments surface especially hydrophobic organics such as PAHs and PCBs. The aim of this study is to accomplish a comprehensive investigation of inorganic elements concentration on sediment surface and illustrate their distribution patterns.

\section{Materials and Method}

\subsection{Sampling}

Surface sediment samples (following the directives of the national program for assessment of marine pollution of highly contaminated Italian coastal areas) were collected from 96 locations (Figure 1) of Naples and Salerno bays in May 2000. A differential global positioning system (DGPS) was used to identify each location precisely. 23 samples were collected using a box-corer with an inner diameter of $25 \mathrm{~cm}$, of which we have used the superficial sediments to be analyzed. 63 samples were collected by grab. Each sample was divided into three and stored in $4^{\circ} \mathrm{C}$ freezer.

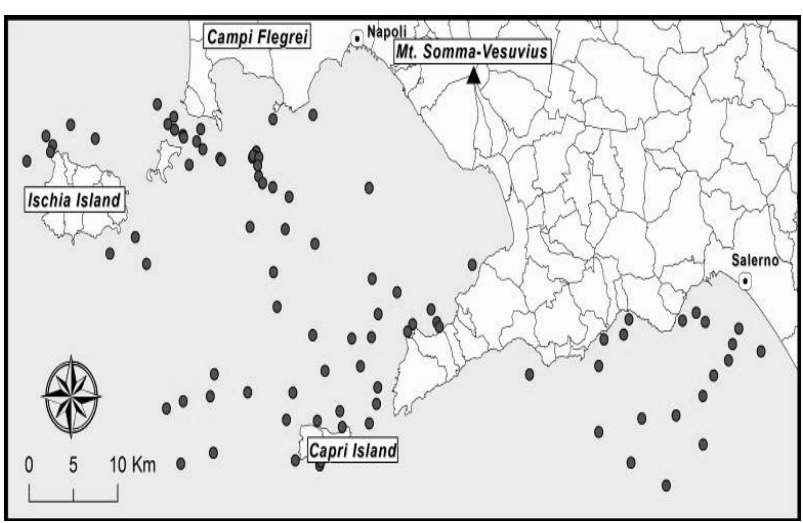

Figure 1. Study area and samples locations. 


\subsection{Chemical Analyses and Quality Control}

The all air-dried sediment samples were sieved and $30 \mathrm{~g}$ of the $<150 \mu \mathrm{m}$ fraction was retained for analysis of 53 elements (Table 1). Analyses were carried out by Acme Analytical Laboratories Ltd. (Vancouver, Canada), through its Italian affiliate (Norwest Italia Srl, Napoli). Each sample was digested in a modified aqua regia solution and analyzed by inductively coupled plasma-mass spectrometry (ICP-MS) and atomic emission spectrometry (ICP-AES). Specifically, a $15 \mathrm{~g}$ split of the pulp was digested in $45 \mathrm{ml}$ of the aqua regia mixture (1 part concentrated hydrochloric acid to 1 part nitric acid to 1 part deionised water) at $90^{\circ} \mathrm{C}$ for $1 \mathrm{~h}$. The solution was taken to a final volume of $300 \mathrm{ml}$ with $5 \% \mathrm{HCl}$. Aliquots of sample solution were aspirated into a Jarrel Ash Atomcomp 975 ICP-Emission Spectrometer and a Perkin Elmer Elan 6000 ICP-Mass Spectrometer.

Table 1. Rotating component matrix.

\begin{tabular}{|c|c|c|c|}
\hline \multirow{2}{*}{ Element } & \multicolumn{3}{|c|}{ Component } \\
\hline & 1 & 2 & 3 \\
\hline $\mathrm{Cu}$ & .424 & .786 & .345 \\
\hline $\mathrm{Pb}$ & .392 & .299 & .788 \\
\hline $\mathrm{Zn}$ & .251 & .655 & .676 \\
\hline $\mathrm{Ag}$ & -.005 & -.141 & .838 \\
\hline $\mathrm{Ni}$ & -.006 & .981 & .035 \\
\hline $\mathrm{Co}$ & .167 & .920 & .063 \\
\hline $\mathrm{U}$ & .884 & -.161 & .122 \\
\hline $\mathrm{Au}$ & .105 & -.048 & .944 \\
\hline $\mathrm{Th}$ & .853 & .307 & .147 \\
\hline $\mathrm{Bi}$ & .126 & .408 & .781 \\
\hline V & .609 & .541 & .163 \\
\hline $\mathrm{La}$ & .894 & -.056 & .122 \\
\hline $\mathrm{Cr}$ & .024 & .671 & .665 \\
\hline $\mathrm{Ti}$ & .722 & -.309 & .015 \\
\hline $\mathrm{Al}$ & .846 & .483 & .116 \\
\hline $\mathrm{Na}$ & .808 & .196 & .147 \\
\hline K & .916 & .133 & .134 \\
\hline $\mathrm{Sc}$ & -.033 & .946 & .005 \\
\hline $\mathrm{Tl}$ & .824 & .353 & .257 \\
\hline $\mathrm{Hg}$ & .163 & .104 & .927 \\
\hline $\mathrm{Sn}$ & .293 & .086 & .878 \\
\hline $\mathrm{Be}$ & .891 & .279 & .207 \\
\hline $\mathrm{Li}$ & .186 & .900 & .090 \\
\hline
\end{tabular}

\subsection{Statistical and Spatial Analysis}

For single element interpreting, all the data should be transformed with proper log-ratio method to avoid negative effect of compositional property [8]. All the information was managed in a GIS georeferenced environment, using ArcGis 9.3 software package. Geodetic reference system is the Universal Transverse Mercator (fuse 33) projection on the ellipsoid World Geodetic System (WGS, 1984). All the geochemical maps were generated using the Multifractal Inverse Distance Weighted (IDW) algorithm as an interpolation method. Factor analysis performed with the IBM SPSS Statistics 19 software package was applied to reduce the number of dimensions and extracting synthetic information about the distribution of elements in the studied environment [1].

\section{Results and Discussion}

Heavy metals concentrations of study area were compared to 3 different marine sediment quality guidelines [5] with the purpose of illustrating contamination level of Naples and Salerno bays (Table 2). Long [7] initializes the estimation of adverse biological effect by collect and summary publications. In his work, ERL represents effect-range low which means below it rarely adverse effects, and ERM represents effect-range median which means above it frequently associated with adverse effects. Canadian sediment quality guidelines [5], shares same idea with Long, and include results recently. In CCME's guideline, IQSG represents interim marine sediment quality guideline and PEL represent probably effect level. Italian 367 [2] set the environment tolerated value based on Italian law.

Pollution levels are compared in Figure 2 by presenting percentage of different category samples. Concentrations of $\mathrm{Zn}, \mathrm{Ag}, \mathrm{Cd}$ and $\mathrm{Cr}$ in sediment seldom exceed adverse effect thresholds in the area, while $\mathrm{Ni}, \mathrm{Hg}, \mathrm{Pb}$ and $\mathrm{Cu}$ have median polluted value which may cause adverse effect to living creatures as well as human beings. Only Arsenic shows values highly dangerous, reflecting probably mostly influence of volcanic sediments from Neapolitan volcanoes (Vesuvius, Campi Flegri, Ischia Island) rather than anthropogenic source.

Figure 3 shows the distribution pattern of selected analyzed elements. Most of heavy toxic metals have a similar distribution. $\mathrm{Ag}, \mathrm{Hg}$ and $\mathrm{Pb}$ aggregates close to Napoli metropolitan area, indicating that intense industrial, agricultural and commercial activities affect these elements distribution pattern. Arsenic is mostly concentrated around Pozzuoli bay, where hydrothermal activity related to Campi Flegrei is documented as being very rich in As [2]. The distributions of $\mathrm{Ni}, \mathrm{Zn}$, and $\mathrm{Cu}$ indicate the water energy decrease from coastal to deep sea and cause finer sediment deposit off gulf. Distribution 
Table 2. Heavy metals concentration comparison with different environmental guidelines.

\begin{tabular}{ccccccccccc}
\hline & $\mathrm{Cu}(\mathrm{ppm})$ & $\mathrm{Pb}(\mathrm{ppm})$ & $\mathrm{Zn}(\mathrm{ppm})$ & $\mathrm{Ag}(\mathrm{ppb})$ & $\mathrm{Ni}(\mathrm{ppm})$ & $\mathrm{Cr}(\mathrm{ppm})$ & $\mathrm{Hg}(\mathrm{ppb})$ & $\mathrm{As}(\mathrm{ppm})$ & $\mathrm{Cd}(\mathrm{ppm})$ \\
\hline Average & 26.4 & 39.24 & 68.56 & 103.28 & 20.29 & 26.28 & 97.65 & 16.85 & 0.1 \\
$10.00 \%$ & 7.61 & 20.13 & 35.64 & 31 & 6.98 & 8.92 & 21.7 & 9.68 & 0.05 \\
$25.00 \%$ & 14.45 & 26.18 & 63.23 & 46.5 & 11.8 & 16 & 42.25 & 12 & 0.07 \\
$50.00 \%$ & 26.62 & 35.5 & 71 & 71 & 21.6 & 27.8 & 79 & 14.35 & 0.09 \\
$75.00 \%$ & 37.81 & 47.47 & 84.43 & 109.5 & 27.7 & 35.75 & 116.25 & 17.45 & 0.11 \\
Median & 29 & 69.7 & 106 & 519 & 7.5 & 38.6 & 435 & 12.3 & 0.11 \\
MAD & 12 & 34.4 & 35.8 & 450 & 14.1 & 12.6 & 356 & 3.05 & 0.03 \\
Minimium & 3 & 9 & 16 & 17 & 2 & 3 & 3 & 5 & 0.02 \\
Maxmium & 72 & 128 & 178 & 1012 & 40 & 74 & 864 & 74 & 0.19 \\
ER-L & 34 & 46.7 & 150 & 1000 & 20.9 & 81 & 150 & 8.2 & 1.2 \\
ER-M & 270 & 218 & 410 & 3700 & 51.6 & 370 & 710 & 70 & 9.6 \\
ISQG & 18.7 & 30.2 & 124 & & & 52.3 & 130 & 7.24 & 0.7 \\
PEL & 108 & 112 & 271 & & & 160 & 700 & 41.6 & 4.2 \\
Italian 367 & & 30 & & & 30 & 50 & 300 & 12 & 0.3 \\
\hline
\end{tabular}

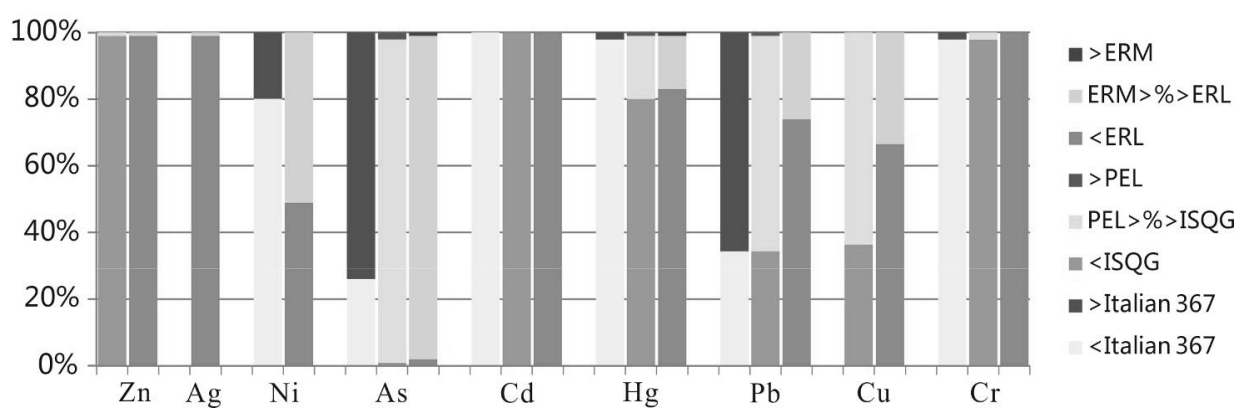

Figure 2. Percentage of different sediment category divided by environmental guidelines. Brown bar shows the percentage of samples that exceed ERM, pink bar shows that between ERL and ERM while green bar shows that below ERL. Red bar represents that exceed PEL, yellow one shows that between PEL and ISQG and blue one represents that below ISQG. Dark grey bars shows percentage exceed Italian 367, light grey shows that below it.

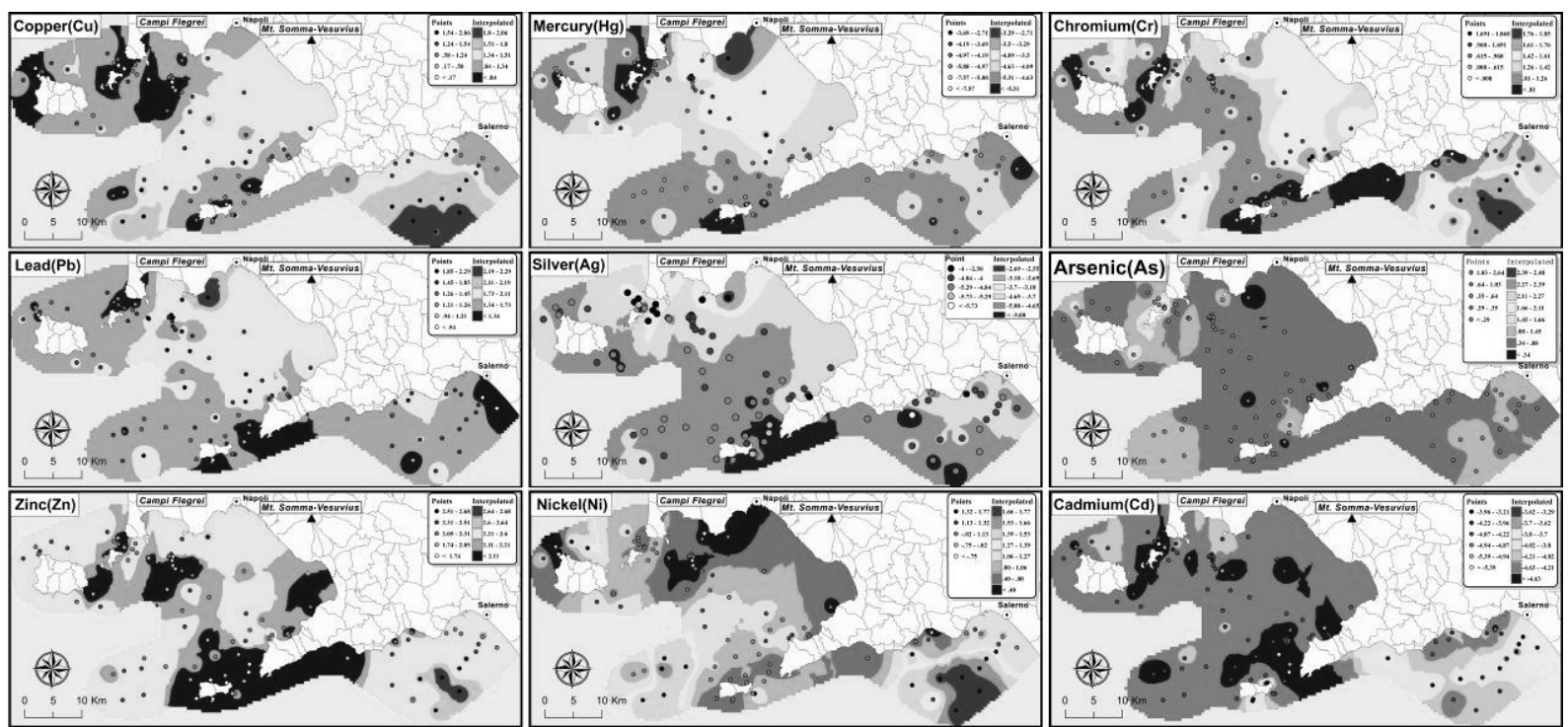

Figure 3. Single elements distribution in Napoli and Salerno Gulf. 
pattern of Chromium indicate combination of anthropogenic effect and water energy effect.

To understand the distribution modes of the different heavy metals and discriminate the different sources, R-mode factor analysis (FA) on 23 of 53 analyzed elements was carried out. The factor model three, accounting $84.9 \%$ of data variability, have been chosed. The elements are considered to describe effectively the composition of factors if the loading is over 0.51 . The associations of the three-factor model are $\mathrm{F} 1 \mathrm{~K}, \mathrm{La}, \mathrm{Be}, \mathrm{U}, \mathrm{Th}$, $\mathrm{Al}, \mathrm{Tl}, \mathrm{Na}, \mathrm{Ti}, \mathrm{V})$ accounted for $32.5 \%$ of data variability, F2 (Ni, Sc, Co, Li, Cu, Cr, Zn, V) accounted for $27.4 \%$ of data variability and $\mathrm{F} 3(\mathrm{Au}, \mathrm{Hg}, \mathrm{Sr}, \mathrm{Ag}, \mathrm{Pb}, \mathrm{Bi}, \mathrm{Zn}, \mathrm{Cr}$ ) accounted for $24.9 \%$ of data variability. Figure 4 shows the distribution pattern of the three association factor scores.

F1 association represents the elements whose distribution is mostly of geogenic source, meaning that human activities have little, control on their behavior in Naples and Salerno bays. F2 represents elements mainly influenced by water energy. F3 is the most anthropogenic factor, showing intense human activities of the Naples

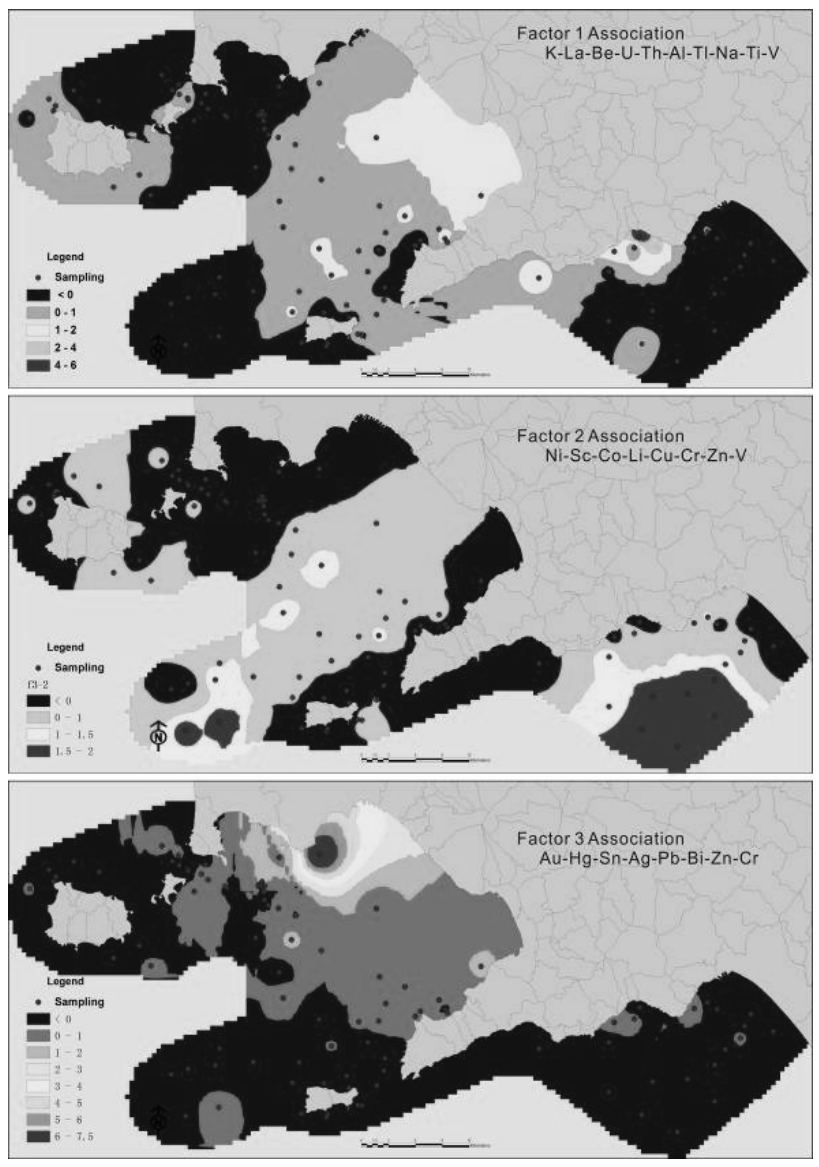

Figure 4. Factor score association maps. metropolitan area as the main source for this 9 elements distribution patterns. The latter is in agreement with the results obtained by Cicchella et al., 2005 for volcanic soils of the metropolitan and provincial areas of Napoli.

\section{Acknowledgements}

Authors thank the C.N.R. Istituto Geomare Sud a Napoli to provide samples and corresponding data, and Dr. Monica Capodanno for sediment storage and disposal. This preliminary study is part of a more comprehensive $\mathrm{PhD}$ program of $\mathrm{M}$. Wang, aimed at the study as well of Persistent Organic Pollutants (POP), such as PAH and PCBs, by SERS laboratory and in situ experimental researchs to understand the behaviour of POP with time.

\section{REFERENCES}

[1] S. Albanese, B. De Vivo, A. Lim and D. Cicchella, "Geochemical Background and Baseline Values of Toxic Elements in Stream Sediments of Campania Region (Italy)," Journal of Geochemical Exploration, Vol. 93, No. 1, 2007, pp. 21-34. doi:10.1016/j.gexplo.2006.07.006

[2] S. Albanese, et al., "Geochemical Baselines and Risk Assessment of the Bagnoli Brownfield Site Coastal Sea Sediments (Naples, Italy)," Journal of Geochemical Expltion, Vol. 105, No. 1-2, 2010, pp. 19-33. doi:10.1016/j.gexplo.2010.01.007

[3] D. Cicchella, "Palladium and Platinum Concentration in Soils from the Napoli Metropolitan Area, Italy: Possible Effects of Catalytic Exhausts," The Science of The Total Environment, Vol. 308, No. 1-3, 2003, pp. 121-131. doi:10.1016/S0048-9697(02)00632-0

[4] D. Cicchella, B. De Vivo and A. Lima, "Background and Baseline Concentration Values of Elements Harmfull to Human Healt in the Volcanic Soils of the Metropolitan Provincial Area of Napoli (Italy)," Geochemistry: Exploration-Environment-Analyses, Vol. 5, 2005, pp. 29-40. doi:10.1144/1467-7873/03-042

[5] CCME and C.C.C.o.M.o.t., "Canadian Sediment Quality Guidelines for the Protection of Aquatic Life. Canadian Environmental Quality Guidelines," In: Environment, C.C.o.M.o.t., Ed., MB, Winnipeg, 2002.

[6] E. R. Long, L. J. Field and D. D. MacDonald, "Predicting Toxicity in Marine Sediments with Numerical Sediment Quality Guidelines," Environmental Toxicology andChemistry, Vol. 17, No. 4, 1998, pp. 714-727. doi:10.1002/etc. 5620170428

[7] E. R. Long, D. D. MacDonald, S. L. Smith and F. D. Calder, "Incidence of Adverse Biological Effects within Ranges of Chemical Concentrations in Marine and Estuarine Sements," Environmental Management, Vol. 19, No. 1, 1995, pp. 81-97. doi:10.1007/BF02472006

[8] C. Reimann, et al., "The Concept of Compositional Data Analysis in Practice - Total Major Element Concentrations in Agricultural and Grazing Land Soils of Europe," Science of the Total Environment, Vol. 426, 2012, pp. 
196-210. doi:10.1016/j.scitotenv.2012.02.032

[9] M. Sprovieri, et al., "Heavy metals, Polycyclic Aromatic Hydrocarbons and Polychlorinated Biphenyls in Surface
Sediments of the Naples Harbour (Southern Italy). Chemosphere," Vol. 67, No. 5, 2007, pp. 998-1009. doi:10.1016/j.chemosphere.2006.10.055 